\title{
Is common the rotator cuff tear in the calcific tendinitis?
}

\author{
Jong-Hun Ji, Jae-Hoon Kim \\ Department of Orthopedic Surgery, Daejeon St. Mary's Hospital, College of Medicine, The Catholic University of Korea, Daejeon, Korea
}

Little information is available about calcific tendinitis of the shoulder combined with rotator cuff tears. The diagnosis and treatment of general calcific tendinitis of the shoulder is well established [1]. However, calcific tendinitis and coexisting rotator cuff tear have completely different disease characteristics and these concerns have prompted research on the true incidence of combined rotator cuff tears in calcific tendinitis and their management. The relationship between calcifying tendinitis and rotator cuff tear remains controversial. Previously, it was strongly believed that these entities could not coexist [2]. Calcific tendinitis and rotator cuff tear are common causes of the chronic shoulder pain. However, the pathogenesis, age predominance, and treatment of calcific tendinitis and rotator cuff tears are completely different. Calcific tendinitis usually peaks in the fifth decade of life, whereas rotator cuff tendon tear continues to increase with age [3]. Also, the true incidence of rotator cuff tears in calcific tendinitis of a Korean population is not well known. There have been few studies about calcific tendinitis combined with rotator cuff tear, especially in a Korean population.

In a study by Yoo et al. [4] entitled "Calcific tendinitis of the shoulder in the Korean population: demographics and its relation with coexisting rotator cuff tear" the authors investigated the demographic, clinical, and radiological factors of calcific tendinitis of the shoulder joint in a large number of Koreans and calculated the prevalence of rotator cuff tear associated with calcific tendi- nitis. This was a multicenter study involving a large population. This retrospective study enrolled 506 patients diagnosed with calcific tendinitis of the shoulder at 11 major training hospitals nationwide.

Calcific deposits are often located 1 to $2 \mathrm{~cm}$ from the insertion of the supraspinatus tendon on the greater tuberosity and often cause severe shoulder pain and limited daily activities [3,5]. Typical calcific tendinitis shows variable functional impairment and symptoms, ranging from months to years; these symptoms were typically self-limiting [5,6]. Most patients (nearly 90\%) can be treated nonoperatively, which includes activity modification, rest, physiotherapy, cold pack or hot pack massage, ultrasound, extracorporeal shock wave therapy, needle lavage, subacromial steroid injection and nonsteroidal anti-inflammatory medications. Although the majority of these patients respond to the above conservative treatments, some patients show persistent shoulder pain and often require operative management.

Surgical treatment should be considered when conservative measures have failed, or when coexisting rotator cuff tear requiring repair is confirmed by radiologic evaluation such as magnetic resonance imaging (MRI) and ultrasonography (US). Recently, arthroscopic debridement of calcific deposits and rotator cuff repair have been found to yield excellent functional results and high patient satisfaction. However, de Witte et al. [7,8] reported that pain and discomfort of the shoulder still persisted in more

Received: February 14, 2021 Revised: February 14, 2021 Accepted: February 19, 2021

Correspondence to: Jong-Hun Ji

Department of Orthopedic Surgery, Daejeon St. Mary's Hospital, College of Medicine, The Catholic University of Korea, 64 Daeheung-ro, Jung-gu, Daejeon 34943, Korea

Tel: +82-42-220-9530, Fax: +82-42-221-0429, E-mail: jijh87@gmail.com, ORCID: https://orcid.org/0000-0003-1087-3254

Financial support: None.

Conflict of interest: None.

Copyright@ 2021 Korean Shoulder and Elbow Society. All Rights Reserved.

This is an Open Access article distributed under the terms of the Creative Commons Attribution Non-Commercial License (http://creativecommons.org/licenses/by-nc/4.0/) which permits unrestricted non-commercial use, distribution, and reproduction in any medium, provided the original work is properly cited. 
than $50 \%$ of patients even after 14 years of follow-up, and that female sex, dominant arm involvement, bilateral disease, longer duration of symptoms, and multiple calcifications were associated with inferior outcomes.

In this study, the average age of symptom onset in calcific tendinitis was 55 years, with onset occurring in patients in their 50 s (45\%), 60s (23\%), and 40s (21\%), respectively. It tended to be more prevalent in females. About $71 \%$ of patients had a high rate of nightly pain. For treatment, oral analgesics (93\%) were the most common, followed by steroid injection therapy (53\%). In total, $79 \%$ of cases were in the dominant arm, $19 \%$ in the non-dominant arm, and $12.6 \%$ of patients had a history of trauma before symptoms. The occupation of those who developed calcific tendinitis was unemployed/housekeeping (37\%), laborers (21\%), office workers (19\%), and others (17\%). In total, $21 \%$ engaged in regular exercise and $15 \%$ exercised their shoulders. The current smokers were $42(8 \%)$, diabetes $(12 \%)$, thyroid disease (6\%), and rheumatic disease (3\%) were found. Among $377 \mathrm{fe}-$ male patients, $47 \%$ had experienced menopause, and $10 \%$ had a history of obstetric disease.

One arthrography study showed that a rotator cuff tear coexists in approximately $25 \%$ of patients presenting with calcific tendinitis [9]. Another study by Hsu et al. [10] showed that calcific tendinitis and rotator cuff tear were concomitant in $28 \%$ of patients on shoulder angiography and that calcium deposits were rather small in patients with rotator cuff tear. Compared to previous studies, this study using sonography or MRI showed a low incidence of combined rotator cuff tears in calcific tendinitis. Among 383 patients (76\%), 59 (15\%) had rotator cuff tears, including 15 (3.9\%) full-thickness tears, 22 (5.7\%) bursal side partial tears and $22(5.7 \%)$ articular side partial tears on US or MRI. Without arthroscopic or open diagnosis of rotator cuff tears, the diagnostic accuracy of US or MRI alone may have affected the reliability of the study.

As a diagnostic tool, MRI is often used to diagnose combined rotator cuff tears in calcific tendinitis. The calcific materials (artifacts) could prevent clear imaging of rotator cuff tears. If the calcific deposits did not occur in the same location as the rotator cuff tear, the tears were easy to diagnose. However, if the location of the calcific deposit coincided with the site of rotator cuff tear, it can be difficult to differentiate rotator cuff tears from calcific tendinitis. Even though MRI technology has improved, rotator cuff tear combined with calcific tendinitis in an adjacent location are difficult to diagnose owing to calcific material artifacts. In particular, low signal fragments of calcification or signs of tendinitis can overlook partial thick rotator cuff tears in MRI, often resulting in higher than expected signals in fluid-sensitive se- quences.

Even though the main cause of shoulder pain was calcific deposits, rotator cuff tear could be a cause of symptomatic shoulder pain. In this study, the authors [4] suggested that a poor prognosis was shown by patients with persistent symptoms, old age, patients with recurring symptoms, and patients with menstrual irregularities further radiographic study to evaluate rotator cuff tear might be needed in some calcific tendinitis patients with older age and recurrent symptoms.

Shoulder surgeons should be cautioned about rotator cuff tears as a comorbidity in calcific tendinitis and also should be aware of the accuracy limitations of sonographic or MRI evaluation of combined rotator cuff tears. Furthermore, in long-standing calcific tendinitis combined with rotator cuff tears, simultaneous rotator cuff repair with calcific deposit removal should be considered to improve clinical outcomes.

\section{ORCID}

Jong-Hun Ji

https://orcid.org/0000-0003-1087-3254

Jae-Hoon Kim

https://orcid.org/0000-0003-1565-9978

\section{REFERENCES}

1. Kim MS, Kim IW, Lee S, Shin SJ. Diagnosis and treatment of calcific tendinitis of the shoulder. Clin Shoulder Elb 2020;23: 210-6.

2. McLaughlin HL, Asherman EG. Lesions of the musculotendinous cuff of the shoulder. IV. Some observations based upon the results of surgical repair. J Bone Joint Surg Am 1951;33:7686.

3. Uhthoff HK, Loehr JW. Calcific tendinopathy of the rotator cuff: pathogenesis, diagnosis, and management. J Am Acad Orthop Surg 1997;5:183-91.

4. Yoo YS, Park JY, Kim MS, Cho NS, Lee YB, Cho SH, et al. Calcific tendinitis of the shoulder in the Korean population: demographics and its relation with coexisting rotator cuff tear. Clin Shoulder Elbow 2021;24:21-6.

5. Sansone V, Maiorano E, Galluzzo A, Pascale V. Calcific tendinopathy of the shoulder: clinical perspectives into the mechanisms, pathogenesis, and treatment. Orthop Res Rev 2018;10: 63-72.

6. Harvie P, Pollard TC, Carr AJ. Calcific tendinitis: natural history and association with endocrine disorders. J Shoulder Elbow Surg 2007;16:169-73.

7. de Witte PB, van Adrichem RA, Selten JW, Nagels J, Reijnierse M, Nelissen RG. Persistent shoulder symptoms in calcific tendi- 
nitis: clinical and radiological predictors. Ned Tijdschr Geneeskd 2016;160:D521.

8. de Witte PB, van Adrichem RA, Selten JW, Nagels J, Reijnierse M, Nelissen RG. Radiological and clinical predictors of longterm outcome in rotator cuff calcific tendinitis. Eur Radiol 2016;26:3401-11.
9. Jim YF, Hsu HC, Chang CY, Wu JJ, Chang T. Coexistence of calcific tendinitis and rotator cuff tear: an arthrographic study. Skeletal Radiol 1993;22:183-5.

10. Hsu HC, Wu JJ, Jim YF, Chang CY, Lo WH, Yang DJ. Calcific tendinitis and rotator cuff tearing: a clinical and radiographic study. J Shoulder Elbow Surg 1994;3:159-64. 